\title{
QUESTÕES DE GÊNERO E SEXUALIDADE NO ESPAÇO PÚBLICO EDUCACIONAL TENDO COMO EIXO DE DEBATE A DISCIPLINA DE ENSINO RELIGIOSO EM ESCOLAS DE RECIFE
}

\author{
GENDER AND SEXUALITY ISSUES IN THE EDUCATIONAL PUBLIC SPACE HAVING A \\ DISCUSSION A DISCIPLINE OF RELIGIOUS EDUCATION IN RECIFE SCHOOLS
}

\author{
CUESTIONES DE GÉNERO Y SEXUALIDAD EN EL ESPACIO PÚBLICO \\ EDUCACIONAL TENIENDO COMO EJE DE DEBATE LA DISCIPLINA DE \\ ENSEÑANZA RELIGIOSO EN ESCUELAS DE RECIFE
}

\begin{abstract}
Aurenéa Maria de Oliveira ${ }^{1}$, Marcelo Henrique Gonçalves de Miranda², Maria Amanda Micaely Pinheiro da Silva ${ }^{3}$
\end{abstract}

\begin{abstract}
RESUMO
Este artigo, oriundo dos resultados de pesquisa de iniciação científica realizada na UFPE (2015-2016), pesquisa esta, por sua vez, vinculada a projeto contemplado pelo Edital Universal do CNPq (chamada no 14/2013), teve como objetivo examinar as falas de gestores, docentes da disciplina de Ensino Religioso (ER) e representantes das secretarias de educação municipal e estadual da cidade de Recife sobre questões de gênero e sexualidade, entrecruzando esse debate à presença ou não de um componente curricular que aborda religiões na escola pública. Assim, buscou-se compreender como são construídos discursivamente significados em torno das temáticas mencionadas, destacando o lugar que mulheres sexualmente marginalizadas como lésbicas, bissexuais e transexuais ocupam dentro das cosmologias religiosas trabalhadas na disciplina em questão. $\mathrm{O}$ trato do material, feito a partir de concepções teóricas de gênero e sexualidade pós-estruturalistas e de um exame metodológico apoiado na Análise de Discurso (AD) francesa, revelou a forte presença de um discurso que ao invés de propor o diálogo sobre as diferenças sexuais, opostamente, invisibiliza conteúdos sobre gênero e sexualidade nas aulas de ER, reforçando posturas estigmatizadoras e preocupantes, sobretudo nos dias atuais em que essas discussões correm o risco de não serem mais temas transversais nos espaços educacionais.
\end{abstract}

PALAVRAS-CHAVE: Gênero. Sexualidade. Ensino Religioso em Escolas de Recife.

\section{ABSTRACT}

This article, derived from the results of research of scientific initiation carried out at UFPE (2015-2016), this research, in turn, linked to a project contemplated by the CNPq Universal Call Notice (called no 14/2013), aimed to examine the lines (RE) and representatives of the municipal and state education departments of the city of Recife on issues of gender and sexuality, intersecting this debate with the presence or not of a curricular component that addresses religions in the public school. Thus, we sought to understand how discursively meanings are built around the themes mentioned, highlighting the place that sexually marginalized women

\footnotetext{
${ }^{1}$ Pós-doutorado - Pontifícia Universidade Católica do Paraná (PUCPR) - Curitiba, PR - Brasil. Doutora em Sociologia - Universidade Federal de Pernambuco (UFPE) - Recife, PE - Brasil. Professora do Programa de Pós Graduação em Educação - Universidade Federal de Pernambuco (UFPE) - Recife, PE - Brasil. E-mail: aurenea@yahoo.com.br

${ }^{2}$ Doutor em Sociologia - Universidade Federal de Pernambuco (UFPE) - Recife, PE - Brasil. Professor permanente do Programa de Pós-graduação - Universidade Federal de Pernambuco (UFPE) - Recife, PE - Brasil. E-mail: mm.marcelohenrique@yahoo.com.br

${ }^{3}$ Graduanda em Pedagogia - Universidade Federal de Pernambuco (UFPE) - Recife, PE - Brasil. E-mail: amandamicaely@hotmail.com
}

Submetido em: 27/10/2016 - Aceito em: 24/06/2018
(C) ETD- Educação Temática Digital
Campinas, SP
v. $20 \quad$ n.4
p. $864-886$
out./dez. 2018 
like lesbians, bisexuals and transsexuals occupy within the religious cosmologies worked on in the discipline in question. The treatment of the material, based on post-structuralist theoretical conceptions of gender and sexuality and a methodological examination supported by the French Discourse Analysis (AD), revealed the strong presence of a discourse that, instead of proposing dialogue about differences sexual orientation, opposes gender and sexuality content in RE classes, reinforcing stigmatizing and worrisome attitudes, especially in the present day when these discussions run the risk of not being cross-cutting themes in educational spaces.

KEYWORDS: Gender. Sexuality. Religious Education in Schools Recife.

\section{RESUMEN}

Este artículo, oriundo de los resultados de investigación de iniciación científica realizada en la UFPE (2015- 2016), investigación esta, a su vez, vinculada al proyecto contemplado por el Edicto Universal del CNPq (Ilamada no 14/2013), tuvo como objetivo examinar las palabras de los gestores, docentes de la disciplina de Enseñanza Religiosa (ER) y representantes de las secretarías de educación municipal y estadual de la ciudad de Recife sobre cuestiones de género y sexualidad, entrecruzando ese debate a la presencia o no de un componente curricular que aborda religiones en la escuela pública. Así, se buscó comprender cómo se construyen discursivamente significados en torno a las temáticas mencionadas, destacando el lugar que mujeres sexualmente marginadas como lesbianas, bisexuales y transexuales ocupan dentro de las cosmologías religiosas trabajadas en la disciplina en cuestión. El trato del material, hecho a partir de concepciones teóricas de género y sexualidad postestructuralistas y de un examen metodológico apoyado en el Análisis de Discurso (AD) francesa, reveló la fuerte presencia de un discurso que en vez de proponer el diálogo sobre las diferencias y en el caso de las mujeres, en las clases de ER, reforzando posturas estigmatizadoras y preocupantes, sobre todo en los días actuales en que esas discusiones corren el riesgo de no ser más temas transversales en los espacios educativos.

PALABRAS CLAVE: Género. La sexualidad. La educación religiosa en las escuelas Recife.

\section{INTRODUÇÃO}

Enquanto espaço educativo, as instituições de ensino devem ter como objetivo contribuir com a formação cognitiva, individual e política dos indivíduos. Sendo assim, o debate sobre identidade, orientação sexual e gênero deve ser garantido no currículo e conteúdo escolar, favorecendo a um olhar mais democrático acerca da diversidade, pois:

... na escola, a convivência entre as crianças possibilita diferentes aprendizagens, as quais favorecem à socialização e internalização de novas crenças, novos comportamentos, novas formas de relacionamentos, como também a vivência com outras culturas e experiências em torno de diferentes aspectos, dentre eles, a sexualidade (AQUINO; MARTELLI, 2012, p. 6).

Revisitando o marco histórico acerca da educação sexual no Brasil, é possível perceber conquistas e recuos sociais sobre os quais a concepção de sexualidade se apoiou. Contudo, é fato que a escola nem sempre esteve preparada para discutir esta temática, principalmente com indivíduos que estão em processo de descoberta de sua orientação. Neste aspecto, a educação enquanto instituição, tende à disciplinar corpos, ensinando-os padrões aceitos socialmente, enquanto o currículo escolar, como mecanismo de controle social, possui cunho ideológico, expressando a cultura dominante que determina e seleciona, de forma arbitrária, conteúdos que serão ensinados em detrimento de outros que serão descartados (OLIVEIRA, 2013, 2014, 2016).

(C) ETD- Educação Temática Digital Campinas, SP $\quad$ v.20 $\quad$ n.4 $\quad$ p.864-886 out./dez. 2018


Diante disso, a recente tendência de se querer retirar as discussões de gênero e sexualidade da escola, está baseada, entre outros fatores, em conceitos religiosos, crenças, tabus e preconceitos da cultura dominante que dificultam a ação do professor e da professora diante das expressões/diferenças sexuais, pois, tais pré-concepções, tendem a cristalizar padrões de comportamentos, relações entre os gêneros e vivências da sexualidade. Há tentativas de imposição dessas conceituações como verdades e modelos perfeitos, haja vista que transgredi-los ocasiona a marginalização do transgressor ou da transgressora (AQUINO; MARTELLI, 2012).

O currículo assim apresenta/representa disputas advindas do campo social, enunciando discursos organizados em momentos contingentes e permeados por disputas hegemônicas de significação, que podem implicar em situações de conflito entre os atores envolvidos nos processos articulatórios, estes processos perpassados por relações de poder ante a definição/postulação de propostas curriculares (LOPES; MACEDO, 2011).

Visto que o contexto escolar se preocupa com o desenvolvimento do ser, problematizando, entre tantos aspectos, os sexuais e de gênero, a presença da disciplina de Ensino Religioso nas escolas públicas brasileiras, em tese, deve se esforçar para contribuir com a formação de um cidadão em diálogo com a sociedade diversificada existente, reconhecendo o pluralismo religioso, a neutralidade confessional do Estado e das instituições públicas, ou sua laicidade, igualmente, reconhecendo o direito do indivíduo viver com ou sem religião. Neste sentido, tal disciplina poderia contemplar as manifestações religiosas, tratando-as como fenômenos culturais e sociais e não como verdades absolutas, ensinando o princípio do respeito às diferentes crenças, identidades, gêneros e orientação sexual, primando pela presença da alteridade (OLIVEIRA, 2013, 2014, 2015, 2016).

Porém, tal componente curricular encontra-se em crise, visto que revela processos de intolerância não só a diferenças religiosas, mas sexuais e de gênero (OLIVEIRA, 2015, 2016). Acerca disso, os discursos predominantes que circulam nesta disciplina refletem a falta de tolerância à medida que tendem a defender determinadas ideologias religiosas, especificamente de cunho cristão, não respeitando a pluralidade presente em diversas áreas nas escolas. Assim, apenas o aparato legal, elaborado pela atual Lei de Diretrizes e Bases da Educação Brasileira - LDB - (BRASIL, 1996), não apresenta a força necessária para o estabelecimento de um ER diversificado e comprometido com a defesa dos direitos humanos e neste aspecto, o discurso de docentes dessa disciplina ainda é fortemente marcado por menções a práticas catequéticas, evidenciando a necessidade premente de construção de processos pedagógicos e curriculares que favoreçam ao hibridismo (OLIVEIRA, 2013, 2014, 2015, 2016).
(C) ETD-Educação Temática Digital
Campinas, SP
v.20 n.4
p. $864-886$
out./dez. 2018 
Sobre o Ensino Religioso no Brasil, faz-se pertinente colocar que desde os tempos do Marquês de Pombal se questiona sobre sua utilidade/funcionalidade, especialmente nas escolas públicas, e ainda hoje há um intenso debate com dois segmentos se destacando dentro dele: o dos que são a favor dessa disciplina, expressando como argumento de defesa a concepção de que ela lida com as diferentes religiões, sendo por conta disso, espaço de debate para a pluralidade humana e consequentemente, para os direitos humanos; e o grupo dos que são contra, alegando que seu passado, sobretudo nos espaços públicos, deixou como legado a catequese e o proselitismo de cunho cristão, especificamente católico, o que promoveu o fomento à intolerância religiosa com as religiões não cristãs, com agnósticos, ateus e os sem religião, entre outros (OLIVEIRA; SILVA, 2012).

Levando em consideração esse legado histórico de intolerância religiosa, advindo da apropriação feita em nosso país do componente curricular em tela, o elegemos para estudo questionando a princípio como ele lida, na atualidade, com a pluralidade não só religiosa, mas com a diversidade sexual e de gênero na escola pública, utilizando como ponto de análise o fato dessas temáticas (orientação sexual e gênero) terem sido adotadas como transversais, nos últimos anos, em espaços escolares (OLIVEIRA, 2013). Indo mais adiante, fora estabelecido como pergunta de pesquisa se o trato e o olhar dado, nas aulas de ER, a esses temas transversos, seria o da problematização e discussão ou o da invisibilidade e indiferença? Sobre isso, sabe-se que a Constituição Brasileira de 1988 (BRASIL, 2016) e a LDB vigente (BRASIL, 1996) no art. 33, reformulado em 1997, permitem as escolas ministrarem o Ensino Religioso, desde que ele seja ofertado como facultativo e assegurado o respeito à diversidade entre as religiões existentes, sem proselitismo; mas com relação às discussões transversais de gênero e sexualidade, qual a orientação?

Nossa hipótese inicial foi a de que devido a uma longa influência da tradição cristã em sua história, tradição esta que contemporaneamente vem sendo revisitada e reafirmada primeiro, pela presença de segmentos evangélicos neste tipo de ensino; segundo, pela ação de autorização, pelo Supremo Tribunal Federal ano passado, do Ensino Religioso confessional em escolas públicas (COSTA; SILVA, 2017); e terceiro, pelas fortes polêmicas relacionadas ao que tem sido denominado de "ideologia de gênero"; por esses motivos, o ER apresentaria mais dificuldade, que outras disciplinas, em lidar com esses temas transversais e neste sentido, o fato dele ter sempre se assumido como proselitista e não laico obstaculizava, no trabalho com seu conteúdo programático, isto é, com as diversas cosmologias religiosas, o trato com as temáticas em destaque, especialmente quando se entrecruza religião, gênero e sexualidade (OLIVEIRA, 2013, 2014, 2015, 2016).

Diante disso, o presente artigo, baseado em resultados de pesquisa de iniciação científica realizada na Universidade Federal de Pernambuco entre 2015-2016 com o apoio do CNPq, pesquisa esta, por sua vez, vinculada a um projeto maior, aprovado pelo Edital
(C) ETD-Educação Temática Digital
Campinas, SP
v.20 n.4
p. $864-886$ out./dez. 2018 
Universal do CNPq (2013-2016), objetivou identificar quais discursos vêem se consolidado, de forma proeminente, ao redor dos conteúdos programáticos da disciplina de Ensino Religioso em escolas públicas municipais e estaduais da cidade de Recife e, qual o lugar que mulheres marginalizadas sexualmente como lésbicas, bissexuais e transexuais ocupam neste processo, isto é, dentro das cosmologias religiosas trabalhadas na referida disciplina.

\section{DISCUSSÃO TEÓRICA: GÊNERO, SEXO E SEXUALIDADE NUMA PERSPECTIVA PÓS-ESTRUTURALISTA}

O feminismo há tempo considera seu projeto como intimamente conectado ao corpo, respondendo e produzindo uma variedade de teorias, às vezes incompatíveis, porém, que o incluem nas suas análises. Nos primórdios desses exames, o foco de boa parte dessas teorias era a contestação do feminino como não inteiramente humano, haja vista que a mulher era entendida nesta época como parte do masculino, sem autonomia própria, da mesma maneira que outros corpos que também tinham a sua humanidade contestada pelo discurso machista, eurocêntrico e misógino do período, como por exemplo, o corpo "negro" ou das classes populares (MIRANDA, 2013).

Neste aspecto, as teorias feministas tiveram que encarar o desafio de enfrentar estas dimensões raciais e de classe, isto é, as criações que constituíram modos específicos de ver e desvalorizar certos tipos de corpos. Sendo que todos estes corpos "diferentes" são potencialmente desestabilizadores, construídos como intrinsecamente imprevisíveis e flutuantes. Não surpreende, por conseguinte, que a habilidade de transcender ao corpo e exercer a racionalidade tenha sido marcada como atributos exclusivos de homens brancos, de classe média/alta, "sadios" e heterossexuais.

As mulheres, como até certo ponto, os outros corpos que também tiveram sua humanidade questionada, foram consideradas enraizadas neles, presas de, e a supostos processos naturais biológicos. Esta feminização naturalizada das noções do corpo indicava assim, que o dualismo Cartesiano, referente a muitos dos estudos contemporâneos, é de fato pouco ou nada neutro. Consequentemente, a teoria feminista tem prestado atenção desde o começo ao corpo, seja para rejeitá-lo, no processo de consecução da igualdade intelectual que segue o padrão masculino, ou para reclamá-lo, como constituição de uma essência de ser mulher (MIRANDA, 2013). Para algumas teorias então, a materialidade do corpo, especialmente na sua forma feminina, é considerada somente como ponto de partida, mas é deixada de lado no percorrer das análises por se considerar que ela cria armadilhas que em vez de subverterem a ordem hegemônica, terminam por reforçá-la (BUTLER, 2008).

Outras abordagens, mais recentes, associadas ao feminismo pós-modernista, tentam, no entanto, enfatizar a importância e a inescapabilidade da corporização

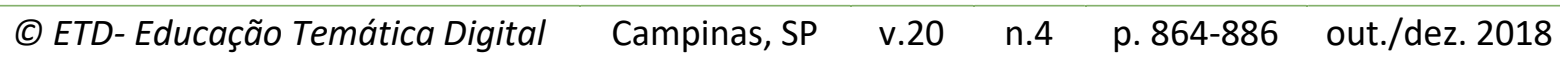


(embodiment) como um construto diferencial e fluído, lócus potencial e não fixo. Tais abordagens, influenciadas pelo pós-estruturalismo, insistem na centralidade do corpo, questionando sua consideração "natural" e empregando um conceito de corporeidade textual - este por sua vez relacionado à concepção de performatividade/performance em Butler - que recai em movimento nos seus significados e implicações (MIRANDA, 2013).

Dessas atuais perspectivas político-feministas, que reorientaram o olhar curioso do investigador social para o corpo e para além de binarismos, brotam propostas interdisciplinares, como a teoria queer e a teoria pós-colonial que se ocupam em desestabilizar a inteligibilidade social baseada em pares dicotômicos, hierarquizados e excludentes (BHABHA, 2005; MISKOLCl, 2012).

Termo utilizado na língua inglesa para se referir de modo pejorativo a homossexuais, queer representa uma crítica aos setores hegemônicos do movimento LGBT (Lésbicas, Gays, Bissexuais e Trans), organizados na lógica das políticas de identidade caracterizadas pela mobilização em torno de identidades (muitas vezes essencializadas), com vistas a buscar reconhecimento e direitos frente ao Estado. Politicamente, queer remete a uma postura radical e de contestação aos valores culturais dominantes (MIRANDA, 2013).

Já na dimensão acadêmica, queer refere-se a uma perspectiva teórica interdisciplinar, desenvolvida originalmente nas Ciências Humanas anglo-saxônicas (principalmente nos EUA) na década de 1990. Suas origens remontam às reflexões de importantes teóricos das décadas anteriores, a saber, dos pós-estruturalistas Michael Foucault e Jacques Derrida, do feminismo negro e lésbico - Gayle Rubin, Gloria Anzaldú e Judith Butler, entre outras (LOURO, 2001).

Assim, homossexuais e outras expressões divergentes da heteronormatividade são trazidas à baila e pensadas como produto social, produto de relações de poder, dominação e subordinação. Este arcabouço conceitual, teórico e analítico, devotado a desconstruir estas normas sociais tidas como naturais, que invisibilizam e desumanizam corpos de homossexuais, é tanto devedor das bases feministas, como dos estudos de gênero e de filósofos que criticaram o estabelecido como Foucault (2007) e outros (OLIVEIRA; MIRANDA, 2013).

Estudos como os de Donna Haraway (2009) e Judith Butler (2003; 2008) buscam descortinar um mundo eminentemente político que condena homossexualidades, bissexualidades, travestilidades, transexualidades e intersexualidades ao silêncio das margens sociais, excluídos de um estado de equidade de direitos. A permanência desta exclusão é importante para legitimar e constituir o incluído heterossexual. Nesse sentido, nas pesquisas de Haraway e Butler, expressões de sexualidade como as mulheres e até certo ponto, os outros corpos que também têm tido sua humanidade questionada, são

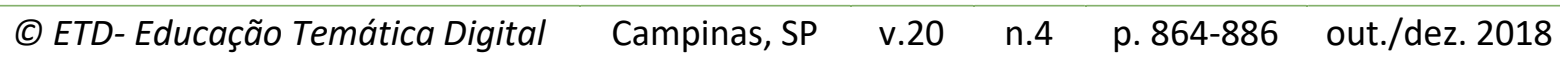


consideradas como enraizadas nos seus corpos, porém, presas a processos contranaturais/culturais e não naturais (MIRANDA, 2013).

Por outro lado, o crescente ativismo tanto feminista quanto de movimentos LGBTTTI (Lésbicas, Gays, Bissexuais, Transexuais, Transgêneros, Travestis e Intersex), tem levado, em alguns contextos, a uma crescente visibilidade, na pauta política e cotidiana, de corpos marcados como diferentes em relação a desestabilizações relativas às categorias de sexo, gênero e sexualidade (MIRANDA, 2013).

No Brasil, o movimento feminista inaugura um contexto social mais aberto às diversidades de gênero e sexualidade. Movimentos feministas no país remontam à década de vinte do século passado e ao contexto de efervescência política da época (como a Semana de Arte Moderna e a Coluna Prestes). Desde então, um crescente espaço de organização e conquistas, que culminou com a instituição do voto feminino em 1933, corrobora com um potencial efeito desestabilizador e reorganizador da sociedade.

Tempos depois, no fim do regime militar, a emergência da sociedade civil contou com um movimento feminista já sólido e apto a empunhar uma bandeira que se desdobrou em uma série de lutas e gradativas conquistas. Assim, desde a instituição do voto feminino (marco de consolidação da primeira fase do movimento) que a ação política feminista contribuiu para criar uma ambiência em que questões das chamadas "minorias" sociais vêem sendo pautadas, debatidas e conquistadas, criando novos fatos sociais, novos hábitos, novos espaços e novos sujeitos para ocupá-los.

O final da ditadura militar marcou também o primeiro momento em que homossexuais (ainda uma palavra única para nomear o sujeito político que atualmente se identifica como LGBTTTI) aparecem na cena pública em meio a uma multidão de organizações civis (FACCHINI, 2005). Estas organizações nascem, entretanto, num mundo em que o movimento feminista brasileiro já havia provocado a nação com suas demandas de gênero e sexualidade (MIRANDA, 2013).

Sem dúvida, os movimentos feministas lograram marcas irrevogáveis de transformações nos modos de ser e agir da sociedade, por exemplo, a Lei Maria da Penha (BRASIL, 2006) que entrou em vigor em 2006 e que exibe sinais de impacto em termos de comportamento, ainda que haja um longo caminho adiante. Todavia, adotando outro olhar sobre o fenômeno do movimento feminista, ressalta-se a centralidade de sua ação para que corpos femininos ocupassem espaços e papéis, até então, reservados ao domínio masculino e que iam de encontro aos modelos tradicionais de mulher.

É importante ressaltar, novamente no contexto do fim da ditadura militar, como as mulheres, mesmo participando do movimento pela liberdade, igualdade e fraternidade, não lograram as mesmas conquistas que os homens heterossexuais conseguiram, dado que elas
(c) ETD- Educação Temática Digital
Campinas, SP
v.20 n.4
p. 864-886 out./dez. 2018 
não eram vistas como sujeitos de direitos. Assim como as mulheres, os sujeitos LGBTTTI, mesmo mobilizados politicamente, ainda se encontram excluídos desses mesmos direitos. No entanto, podemos pensar que o corpo da mulher, mesmo na sua posição subalterna e ou de abjeção, não fora necessariamente estranhado, na sua presença pública, se comparado com outros sujeitos.

Em continuidade e consonância com as lutas feministas, a emergência dos movimentos homossexuais (posteriormente LGBTTTI) e seu reconhecimento pelo Estado brasileiro em 2008, por meio da Conferência Nacional GLBT (Gays, Lésbicas, Bissexuais e Trans), abriu caminho para que expressões de corpos, vozes, jeitos, movimentos aparecessem em público e problematizassem, como fizeram as feministas na década de 1980 com a categoria "gênero", sujeitos universais que representassem a diversidade de identidades (OLIVEIRA; MIRANDA, 2013).

Dentro da teoria feminista há uma concepção do corpo/sexo como biológico e do gênero como uma construção sociocultural. A separação entre as categorias de sexo e gênero ocorre a partir dos trabalhos de John Money que na década de 1940 utiliza pela primeira vez a categoria de gênero como oposição a de sexo. Para ele, sexo diria respeito ao campo biológico, enquanto gênero abarcaria os elementos culturais relativos a ser homem ou ser mulher (PRECIADO, 2002, 2003, 2009). Essa distinção é posteriormente apropriada pelas feministas ao tentarem desnaturalizar as diferenciações entre homens e mulheres. Elas argumentam que nas demarcações dos campos do masculino e do feminino, estariam imbricadas constantes relações de poder (MIRANDA, 2013).

Assim, o gênero não é uma simples categoria analítica; ele é, como as intelectuais feministas têm crescentemente argumentado, uma relação de poder, pois, os padrões de sexualidade feminina são, inescapavelmente um produto do poder dos homens para definir o que é necessário e desejável - um poder historicamente enraizado (WEEKS, 2000).

Pensando desse modo, o gênero é necessariamente atravessado por relações de poder, tendo suas expressões permitidas ou reprimidas de acordo com os padrões vigentes no grupo em questão. Já o sexo, apesar do argumento de que ele estaria sempre ligado aos marcadores biológicos, torna-se impossível pensá-lo separado de gênero. Os modos como podemos enxergar em uma pessoa as características sexuais passam necessariamente pelos aspectos culturais do que comumente se entende como ser homem ou ser mulher; dessa forma, faz muito sentido o argumento butleriano de que o sexo vem sendo tradicionalmente colonizado pelo gênero (BUTLER, 2003, 2008).

Neste aspecto, a questão do sexo, do gênero e da sexualidade é problematizada e desconstruída por meio das produções de Butler. A autora questiona a separação já clássica na teoria feminista entre corpo biológico e gênero como produção sociocultural. Isso é feito
(C) ETD-Educação Temática Digital
Campinas, SP
v.20
n.4
p. $864-886$
out./dez. 2018 
através de uma desconstrução da categoria corpo como biológica ao passo que esse corpo, só ganha significado, em uma construção social.

Os desdobramentos de trabalhos nessa perspectiva de construção sociocultural do gênero, do sexo e da sexualidade vão fundamentar o que tem sido denominado de teoria queer e é dentro das concepções advindas desta que situamos politicamente nosso olhar neste artigo.

\section{METODOLOGIA E RESULTADOS}

Ao defender uma noção de sujeito descentrada, igualmente, uma percepção de identidade fluída (performatividade) e do agente como não dono de sua própria ação, a teoria queer emerge numa conjuntura pós-estrutural em que desarranjos e subversões quebram noções e expectativas. No campo educacional está postura incorpora uma perspectiva subversiva de currículo, formação política de sujeitos e conteúdos programáticos haja vista que, binarismos como macho/fêmea, homem/mulher, masculino/feminino, heterossexual/homossexual - que são considerados a norma padrão dos desejos/sentidos fixos - são deslocados pela ação da lógica performática de nomeação/produção, reprodução e fissuras nessas reproduções dos corpos. Esse olhar possibilita a mudança de uma pedagogia hegemônica naturalizada em relação ao sexo, gênero e sexualidade, para outra contranatural (OLIVEIRA; MIRANDA, 2013).

Assim, a pedagogia queer investe na produção das diferenças, ressaltando a compreensão sobre a instabilidade das identidades, desnaturalizando as concepções e relações de sexo, gênero e lugares sexuais:

\footnotetext{
Os teóricos e teóricas queer fazem um uso próprio e transgressivo das proposições das quais se utilizam, geralmente para desarranjar e subverter noções e expectativas. É o caso de Judith Butler, uma das mais destacadas teóricas queer. Ao mesmo tempo em que reafirma o caráter discursivo da sexualidade, ela produz novas concepções a respeito de sexo, sexualidade, gênero. Butler afirma que as sociedades constroem normas que regulam e materializam o sexo dos sujeitos e que essas "normas regulatórias" precisam ser constantemente repetidas e reiteradas para que tal materialização se concretize. Contudo, ela acentua que "os corpos não se conformam, nunca, completamente, às normas pelas quais sua materialização é imposta", daí que essas normas precisam ser constantemente citadas, reconhecidas em sua autoridade para que possam exercer seus efeitos. As normas regulatórias do sexo têm, portanto, um caráter performativo, isto é, têm um poder continuado e repetido de produzir aquilo que nomeiam e, sendo assim, elas repetem e reiteram, constantemente, as normas dos gêneros na ótica heterossexual (LOURO, 2001, p. 548).
}

Louro (2001) sublinha o fato de Butler ter tomado emprestado da linguística o conceito de performatividade com o intuito de trabalhar sexo e corpos não como descrições, mas como atos de nomeação, ou seja, produção de sujeitos no sentido de que dizer é fazer. Nessa perspectiva, a mesma destaca, citando ainda Butler, que é essa
(C) ETD-Educação Temática Digital
Campinas, SP
v.20 n.4
p. $864-886$ out./dez. 2018 
possibilidade de nomeação que incide sobre a heterossexualidade de modo paradoxal, pois ela abre espaço para o questionamento e a discussão sobre o que não está dentro da lógica heteronormativa (OLIVEIRA; MIRANDA, 2013).

Desse modo, é que um currículo queer faz-se relevante posto que, possibilita desconstruções de argumentos essencialistas, desestabilizando uma inteligibilidade heteronormativa, inclusive nos discursos dos que se dizem simpatizantes da homossexualidade. Tais desconstruções problematizam uma pedagogia hegemônica que naturaliza e fixa significados, dando uma conotação ontológica à homossexualidade, ao gênero e ao sexo. Nas palavras de Louro:

\begin{abstract}
Butler, como outros teóricos queer, volta sua crítica e sua argumentação para a oposição binária heterossexual/homossexual. Esses teóricos e teóricas afirmam que a oposição preside não apenas os discursos homofóbicos, mas continua presente, também, nos discursos favoráveis à homossexualidade. Seja para defender a integração dos/as homossexuais ou para reivindicar uma espécie ou uma comunidade em separado; seja para considerar a sexualidade como originariamente "natural" ou para considerá-la como socialmente construída, esses discursos não escapam da referência à heterossexualidade como norma (LOURO, 2001, p. 549).
\end{abstract}

Diante disso, uma pedagogia e um currículo queer estão voltados para problematizações e produções em torno das diferenças, desconstruindo afirmações que interpelam os sujeitos, descrevendo uns como normatizados e outros como marginalizados. Neste aspecto, como nos expõem, Louro (2001) e Miskolci (2012), os excluídos ou os abjetos são constituintes dos incluídos, pois, para se perceber a existência dos concebidos como "normais" há a necessidade da existência dos tidos como "anormais".

Assim sendo, foi a partir dessa percepção queer de pedagogia e currículo que a pesquisa de iniciação científica "Relações de Gênero e Diversidade Sexual: qual o lugar que mulheres sexualmente marginalizadas ocupam no currículo da disciplina de Ensino Religioso em escolas estaduais e municipais de Recife" teve início, em agosto de 2015 e término em julho de 2016, estando associada ao projeto de pesquisa, aprovado pelo Edital Universal do CNPq (11/2013 a 10/2016), intitulado "Tolerância, Intolerância e Diferenças: como o currículo da disciplina de Ensino Religioso lida com questões que envolvem pluralidade religiosa e sexualidade nas escolas estaduais e municipais de Recife".

Neste aspecto, foi que fazendo uso da metodologia da Análise de Discurso (AD) francesa, a partir dos trabalhos de Michel Pêcheux e Eni Orlandi, foi possível nos apropriarmos dos aparatos necessários para o exame dos dados coletados, refletindo sobre os discursos referentes ao currículo e conteúdos programáticos da disciplina de Ensino Religioso nas escolas públicas estaduais e municipais, da cidade de Recife, pesquisadas. No momento da ida ao campo foi utilizado, como instrumento de pesquisa, um questionário semi-estruturado com questões direcionadas aos sujeitos pesquisados envolvidos com a
(C) ETD-Educação Temática Digital
Campinas, SP
v.20 n.4
p. $864-886$
out./dez. 2018 
disciplina em questão, sendo eles: diretores, professores de ER e representantes das secretarias de educação municipal e estadual de Recife, numa quantidade de seis (06) atores sociais a entrevistar (SILVA; OLIVEIRA, 2016).

A partir da Análise de Discurso de Pêcheux e Orlandi identificamos relações de lugar, de força e de sentido nas falas dos entrevistados, o que nos permitiu compreender posições, conflitos e ideologias que circulam socialmente sobre o ER. Desse modo, concorda-se com a $A D$ quando afirma que não há discurso sem sujeito e sujeito sem ideologia, e que esta se manifesta na língua, sendo condição necessária para a constituição de enunciações e lugares (PÊCHEUX, 1997; ORLANDI, 1999). Assim, através do exame das perspectivas de gênero e sexualidade pós-estruturalistas, pudemos localizar os sentidos predominantes, presentes nos discursos dos atores sociais entrevistados, compreendendo como eles são construídos ao redor do Ensino Religioso e de seus conteúdos programáticos. Isso permitiu entender como o currículo dessa disciplina sofre processos de hibridização e reconfiguração (SILVA; OLIVEIRA, 2016).

Os atores sociais entrevistados foram: 01 professor técnico como representante da secretaria de educação municipal de Recife, 01 professor técnico como representante da secretaria de educação estadual de Recife, 01 professora de ER de escola municipal de Recife, 01 diretor de escola municipal de Recife, 01 professora de ER de escola estadual de Recife, 01 diretora de escola estadual de Recife. Todos permitiram a realização das entrevistas e sua divulgação dentro das condições de anonimato de seus respectivos nomes. Abaixo segue o quadro dos sujeitos participantes da pesquisa.

QUADRO 01 - Entrevistados, Instituições e Funções

\begin{tabular}{|c|l|l|l|}
\hline INSTITUIÇÃo & REDE & CIDADE & REPRESENTANTE \\
\hline Escola Municipal André de Melo & Municipal & Recife & 01 Professora de ER \\
\hline Escola Municipal André de Melo & Municipal & Recife & 01 Diretor/gestor \\
\hline Escola Estadual Poeta Manuel Bandeira & Estadual & Recife & 01 Professora de ER \\
\hline Escola Estadual Poeta Manuel Bandeira & Estadual & Recife & 01 Diretora/gestora \\
\hline Secretaria de Educação & Municipal & Recife & 01 Professor Técnico \\
\hline Secretaria de Educação & Estadual & Recife & 01 Professor Técnico \\
\hline
\end{tabular}

Fonte: (SILVA; OLIVEIRA, 2016).

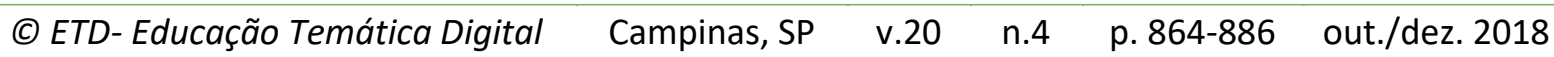


Como componente curricular, do Ensino Religioso pede-se contemporaneamente que contribua para a problematização do sujeito cognitivamente, individualmente e politicamente, tendo para tal, como princípio, o não proselitismo. Assim, para a colaboração com a formação de um cidadão em diálogo com a sociedade plural atual na qual estamos inseridos, o ER deve atuar a partir de orientações que possibilitem às pessoas assumirem suas identidades em sua complexidade. Neste sentido, faz-se necessário compreender quais os discursos pedagógicos e curriculares que envolvem tal componente no trato com as questões de gênero e sexualidade. Diante disso, os dados coletados com os sujeitos entrevistados, envolvidos com o Ensino Religioso, nos apresentam alguns discursos atuantes no processo educativo desta disciplina.

Inicialmente é perceptível um forte discurso atravessado pela ideologia da legalidade para justificar vários aspectos que envolvem o ER, tais como, sua própria oferta nas escolas públicas e o nível educacional no qual está inserido:

Desde que se tornou obrigatório, sempre se ofereceu essa disciplina, pois é lei e temos que cumprir (Gestora da Esc. Est. de Recife).

Ensino Fundamental e essa é a orientação da legislação em vigor. É um componente importante e sua legalidade vem reforçar isso (Representante da Sec. Est. de Recife).

Porque o nível, isso daí quem diz é o currículo da rede, a LDB tá dizendo que é pra ter Ensino Religioso nas escolas nos anos finais do Ensino Fundamental, então temos que ter (Professora da Esc. Mun. de Recife).

No entanto, quando adentramos nas questões sobre os conteúdos programáticos e concepções curriculares para/sobre a disciplina, notamos que uma ideologia catequética e cristã se apresenta, reforçando a necessidade do ER na sala de aula em termos políticos e de cidadania:

Eu ensinei o Pai Nosso, a oração deixada por nosso Senhor Jesus Cristo, então eu ensinei o Pai Nosso, eu escrevi o Pai Nosso no quadro, então, na verdade, eu ensinei pra eles os princípios né, assim, os princípios de um cidadão, de um ser e o respeito que deveria ter com o Cristianismo, com a religião porque essa disciplina é importante para a cidadania né? Para ensinar o respeito de um cristão com outro (Professora da Esc. Est. de Recife).

Vejo a disciplina como politicamente importante para a constituição da cidadania das pessoas. Por conta disso, acho que seu currículo deve contemplar como conteúdos questões que trabalhem a paz, o amor, a tolerância, elementos que todas as religiões cristãs ensinam (Professora da Esc. Mun. de Recife).

Essa tendência ideológica catequética e cristã se manteve, sobretudo quando questionamos o lugar e a necessidade dessa disciplina na grade curricular em seu caráter facultativo:

(C) ETD-Educação Temática Digital Campinas, SP $\quad$ v.20 $\quad$ n.4 $\quad$ p.864-886 out./dez. 2018


Não, ela é uma disciplina como outra qualquer, tem nota e tudo, embora não reprove, mas ela é importante para discutir a paz, a tolerância entre os homens. Ela é tão importante quanto às outras porque ensina o respeito, o amor, a cidadania (Diretor da esc. Mun. de Recife).

Faz parte da grade curricular, como a Geografia, como História, como Matemática, aí o aluno, se ele tá na escola que tem a disciplina, ele tem que participar daquela grade curricular mesmo que seja facultativo porque a disciplina funciona como uma promotora de diálogo entre os alunos, o diálogo ecumênico, cristão que trata do que é universal e comum no seio das religiões; ela é importante para a reflexão, a cidadania, a paz (Professora da Esc. Est. de Recife).

Essa presença ideológica cristã é, contudo, quebrada quando perguntamos sobre a participação de instituições religiosas no planejamento curricular dessa disciplina nas escolas estaduais e municipais de Recife pesquisadas. Neste aspecto, o que ficou discursivamente evidenciado foi a negação da aceitação desses grupos religiosos no processo de disputa de conteúdos e significados políticos em torno da disciplina:

Não, o conteúdo fica muito a cargo da escola, do professor, do que o professor vai selecionar, a escola não tem vínculo nenhum com nenhuma religião específica e o currículo dessa disciplina é de autonomia nossa (Diretora da Esc. Est. de Recife).

Não. Teve uma discussão no início, na formação dessa nova grade curricular a gente teve como assessor o professor Gilbraz que é da Católica; ele participou de alguns encontros intereligiosos, mas não especificamente pra dizer, olhe coloque isso aqui; não existe isso, não existe (Representante da Sec. Mun. de Recife).

Todavia, essas formações enunciativas se modificam novamente quando se questiona a formação docente necessária para lecionar a disciplina; neste caso, o discurso mais proeminente foi o da falta de obrigatoriedade de uma formação específica para lecioná-la, o que fica a cargo da escolha/identificação dos docentes; por sua vez, estas escolhas e identificações são feitas a partir de vínculos ideológicos de pertenças religiosas:

Não tem uma exigência não, geralmente são os professores de Língua Portuguesa, de História, Geografia, Sociologia, sempre o pessoal de humanas que tem interesse em lecionar essa disciplina e eles escolhem a disciplina muitas vezes porque tem suas religiões e se identificam com elas (Diretora da Esc. Est. de Recife).

Não existe, quer dizer, só exige que tenha um curso superior em uma licenciatura, mas não especificamente não diz que você tem que ter tido uma formação nessa área específica. Os professores que geralmente optam em dar essa disciplina são da área de humanas e normalmente gostam de dar as aulas de religião porque já fizeram isso em outros lugares, como em suas religiões (Representante da Sec. Mun. de Recife).

Sobre o conteúdo programático para a disciplina de Ensino Religioso, o discurso predominante dos entrevistados exibiu interfaces com a perspectiva de currículos construídos cotidianamente; essas construções são feitas a partir de ressignificações e hibridizações ocorridas nas salas de aula, mas também de determinações advindas de orientações educacionais:

(C) ETD- Educação Temática Digital Campinas, SP $\quad$ v.20 $\quad$ n.4 $\quad$ p.864-886 out./dez. 2018


Ah, é bem grande, eu não sei te dizer objetivamente, porque a gente dispõe do sistema online, a gente tem o diário online e nesse diário online eles possuem a matriz curricular e o projeto político pedagógico para cada disciplina né, aí a gente dá uma olhada geral e vai adequando o assunto ao dia-a-dia deles (Professora da Esc. Mun. de Recife).

O projeto da disciplina vem das orientações das secretarias, agora a gente adapta esse projeto e o currículo dela ao espaço escolar (Diretora da Esc. Est. de Recife).

Ainda acerca dos conteúdos programáticos, no quesito formulação deles, observamos que o discurso sobre o ER aproxima-se das concepções ideológicas pluralistas, pois assume a diversidade religiosa como temática:

... você tem conteúdos obrigatórios, como por exemplo, o que é religião; o que é religiosidade; quais as religiões que se pode trabalhar, que se tem no Brasil e no mundo, então vem Islamismo, Budismo, Protestantismo, Espiritismo, vem uma obrigatoriedade das religiões afro-brasileiras, segundo a lei 10.639 , a partir da lei 11.645 as indígenas, então, esses conteúdos e os eixos deles, estão nesses documentos, Parâmetros, que a gente espera que se concluam, pra ficar mais claro e, pra ter uma maior orientação aos professores desse componente curricular (Representante da Sec. Est. de Recife).

Os quatro eixos principais são: o primeiro Tradições Religiosas e Culturas, o outro eixo é Textos Sagrados e Interpretações Religiosas, o terceiro eixo é Tempos e Espaços das Espiritualidades e o quarto eixo é Ética entre e para além das Religiões; estamos discutindo e tem um grupo da secretaria presente nisso. Esses eixos têm sido debatidos entre professores, gestores e representantes das secretarias tentando dar conta da variedade de religiões existentes (Representante da Sec. Mun. de Recife).

Mas, quando se questiona sobre o material didático utilizado nas aulas dessa disciplina, a ideologia cristã novamente evidencia-se, deslocando e desbancando a ideologia pluralista:

Não, a escola oferece o material e o professor monta as suas aulas A gente usa muito os livros da editora Vozes que é cristã e já tem tradição de livros cristãos nessa área de Ensino Religioso (Professora da Esc. Est. de Recife).

Sim, é o material que tanto posso dispor da internet como também eu pego nas formações que temos São livros que falam de amor, compaixão, solidariedade.

Não é auto-ajuda, são os que abordam a força da fé, da obra de Deus (Professora da Esc. Mun. de Recife).

Com relação à abordagem das temáticas de gênero e sexualidade nas aulas de ER, envolvendo especificamente conteúdos programáticos acerca do lugar que mulheres sexualmente marginalizadas como lésbicas, bissexuais e transexuais ocupam nas cosmologias religiosas trabalhadas nas escolas, a ideologia que de modo majoritário se apresenta é a da invisibilidade desses temas. A justificativa para essa invisibilidade apóia-se nas relações de lugar e de força que ocorrem não só dentro do espaço escolar, mas também fora dele e que colocam as mulheres, sobretudo, homossexuais, bissexuais e transexuais como "fora do padrão" o que exige grande esforço de diálogo com suas diferenças:

(C) ETD-Educação Temática Digital Campinas, SP $\quad$ v.20 $\quad$ n.4 $\quad$ p.864-886 out./dez. 2018


Não, a gente não tá, vamos dizer assim, autorizado a falar em relação a gênero e sexualidade porque é um assunto bem delicado, bem pessoal, bem complexo, que cabe aí no caso a cada um, então não cabe aqui a escola a tá escolhendo que lado seguir, se é pra ser hetero, se é pra ser bi, se é pra ser qualquer outra coisa, o interesse maior é mostrar ao aluno a religião como uma forma de conforto, consolo, busca, enfim, nada em relação a gênero e orientação sexual (Professora da Esc. Mun. de Recife).

A mulher é vista como as religiões tratam e nas religiões, pelo menos as que conheço, não vejo tratar disso. Sexualidade é muito difícil. A gente busca não mexer com isso porque gera muita confusão (Professora Esc. Est. de Recife).

Olhe, se tratar da pluralidade religiosa é difícil, imagina a sexual. Aqui se a gente aborda as religiões afro-brasileiras, somos ameaçados. Não oriento então o professor de religião a falar disso, porque vai ocorrer briga, a maioria não aceita, não acha que é normal e as meninas, quero dizer, lidar com mulher, com a sexualidade da mulher homossexual, bissexual é complicado; com a trans, transexual, não sei nem como funciona isso, porque só conheço essa história de trans com homem. Tem mulher que é trans também? (Diretor da Esc. Mun. de Recife).

A ideologia da invisibilidade desses temas transversais nos conteúdos programáticos e consequentemente, no currículo do ER, dimensiona-se ainda mais quando perguntamos aos entrevistados se o desconforto causado pelo debate sobre as diferenças e a diversidade sexual entre as mulheres, ocorridos nas aulas dessa disciplina, não poderia ser aproveitado para problematizar estigmas e intolerâncias criados socialmente em torno delas. Nas respostas, observou-se então a presença de discursos marcados pela ideologia da indiferença e da rejeição aos temas de gênero e sexualidade, corroborando com o que pesquisas feitas concluem, no sentido de haver uma relação negativa entre assuntos que envolvam sexo e religião e mais especificamente, gênero, sexo e religião (OLIVEIRA, 2015, 2016). Este discurso é associado a outro, de cunho ideológico biológico que defende que os temas sobre gênero e sexualidade não deveriam ser transversos, e sim, deveriam ficar circunscritos à área da saúde e das ciências da natureza:

Eu acredito que é importante sim, mas eu não acredito que fosse muito funcional, porque como a maioria da nossa população não é uma população muito bem esclarecida, não é uma população que tem uma base familiar né, uma estrutura, onde ainda a cabeça das pessoas tem assim, muitos preconceitos, bloqueios, seria, acredito que muito complexo, delicado e, até mesmo, de uma certa forma perigoso, abordar assim, esse assunto tão, como é que eu posso dizer, polêmico, que inclusive, existe até agressões físicas às pessoas que são de outros, outras tendências, vamos dizer assim, físicas, verbal, nas ruas, mortes, aí, acho complicado; a gente deveria, não sei que solução dar, mas que deveria ser vista de uma forma pra justamente amenizar esse tipo de violência que existe sim, agora como isso seria feito? Não faço ideia, eu mesma evito pra que justamente não exista algum tipo de má interpretação ou que ache que eu esteja fazendo uma apologia ao heterossexualismo, ao homossexualismo ou transsexualismo, enfim. Fica mais fácil esse debate com o pessoal da saúde, da Biologia, mas na área de humanas, religião acho complicado porque gera muito debate, polêmica, entende? (Professora da Esc. Mun. de Recife).

(C) ETD-Educação Temática Digital Campinas, SP $\quad$ v.20 $\quad$ n.4 $\quad$ p.864-886 out./dez. 2018 
Não sei, vamos esperar pra ver como é que vai ficar isso na legislação, mas eu acho que a escola tem que tratar, tem que tratar, deve ser um conteúdo, ou em Biologia, ou em Educação Física, agora que, se for em Ensino Religioso, eu não sei necessariamente, é uma coisa que tem que ser pensada pra entrar como um conteúdo do Ensino Religioso, porque já cabe e já cai dentro de outras disciplinas de saúde, mas para Ensino Religioso, acho inviável (Representante da Sec. Est. de Recife).

Eu não me aprofundei muito em relação às questões de gênero e sexualidade, porque os meus alunos do Ensino fundamental foram os alunos do 60 ano e do 70 ano, então assim, eu preferi que o próprio professor de Ciências, de Biologia, eles direcionassem mais esses assuntos, como eu tava passando pra eles Ensino Religioso, eu preferi falar mesmo dos conceitos básicos, da formação do cidadão, da ética, dos princípios, do laço familiar, eu preferi mais direcionar pra esses assuntos que trazem paz, harmonia e não para temas polêmicos (Professora da Esc. Est. de Recife).

Ainda em relação a essas temáticas, ficou evidente a dificuldade dos entrevistados em conceituar gênero e sexualidade, sobretudo entre os professores. Neste aspecto, tanto gênero, sexo como orientação sexual foram tratados discursivamente a partir de princípios enunciativos que não levavam em consideração perspectivas teóricas pós-estruturalistas sobre eles, sendo entendidos como categorias naturalizadas, reforçando perspectivas, políticas curriculares e ideologias essencialistas:

Gênero e sexo acho que a gente nasce com eles né, a orientação sexual acho que também, pois na sala de aula a gente percebe desde cedo aquele menino mais afeminado, a menina que quer fazer as coisas dos meninos. Mas, como lhe disse não me aprofundei muito nesses temas (Professora da Esc. Est. de Recife).

Sexo vem de Deus. O gênero são os papéis mas, de acordo com o sexo de cada um. Agora os homossexuais, penso que é de pequeno por que, que sabe aquela menina que não é muita afeita à maquiagem, sabe como é, às coisas de mulher. Logo depois a gente fica sabendo que ela tá namorando uma menina na sala (Professora da Esc. Mun. de Recife).

Por fim, sobre os desafios que envolvem a presença de uma disciplina que aborda as religiões no espaço escolar público, que se afirma laico, o que se identificou foi à equivalência entre os conceitos de Ensino Religioso e educação religiosa à medida que os entrevistados adotaram um discurso que entende ideologicamente a religião como algo transcendental, isto é, como "verdades" que se encontram acima dos seres humanos, e não como algo imanente, isto é, cosmovisões/cosmologias construídas por nós:

Se essa disciplina é obrigatória de ser dada na escola ela tem que tratar das verdades religiosas de cada religião. É uma educação religiosa na questão ética, moral que envolve a formação cidadã dos indivíduos (Diretora da Esc. Est. do Recife).

A laicidade significa não escolher uma religião, mas na disciplina de Ensino Religioso não dá para escapar da educação religiosa porque a gente tem que ensinar o que é certo e errado dentro das religiões, o que é verdadeiro e isso passa
(C) ETD-Educação Temática Digital
Campinas, SP
v. 20
n. 4
p. $864-886$
out./dez. 2018 
pelo dogma, pela fé, verdade de cada um, inclusive do professor (Professora da Esc. Est. do Recife).

Não sei como the responder essa questão porque é complexa. Dialogar religião e laicização é como se fossem coisas opostas e fazer isso na disciplina de Ensino religioso não sei. Trabalho na educação há muito tempo e lhe digo não tem como na sala de aula um professor ou professora não puxar a sardinha para o seu lado, daí o Ensino Religioso ser confundido com educação religiosa (Diretor da esc. Mun. do Recife).

Essa perspectiva de equivalência entre Ensino Religioso e educação religiosa vem reforçar a dificuldade de se trabalhar com as temáticas sobre gênero e sexualidade na disciplina em tela, tendo em vista que a não compreensão da religião como um fenômeno cultural e social dificulta, numa perspectiva de relação de lugar e de posição de sujeitos hierarquizadas, o debate e a problematização do status que mulheres sexualmente marginalizadas ocupam dentro das cosmovisões de mundo religiosas que são trabalhadas no componente curricular analisado. Essa não localização do lugar dessas mulheres reitera politicamente, a reverberação de discursos circulantes que as entendem como seres abjetos, desprestigiadas em seus corpos e sexualidades.

Neste aspecto, é fato que as várias cosmologias religiosas se encontram presentes no desenvolvimento de processos de não respeitabilidade da diferença do outro; não foi por acaso que o termo intolerância foi aplicado primeiro ao campo religioso e depois ao campo político. Sendo assim, entender que as religiões, entre outros elementos culturais, são promotoras de hierarquias, estigmas, preconceitos etc., estes baseados em princípios de fé e de dogmas entendidos como verdades absolutas e inquestionáveis, pode ser relevante na perspectiva de combate à homofobia e à misoginia (OLIVEIRA, 2015, 2016).

\section{CONSIDERAÇÕES FINAIS}

Na atual LDB (BRASIL, 1996), o Ensino Religioso é ofertado obrigatoriamente pelas instituições educacionais públicas, porém esta oferta não é impositiva por sua matrícula ter caráter facultativo; mas, seu trabalho formativo deve afastar-se do proselitismo, vindo a contemplar de modo laico, ou seja, sem apologia a nenhuma religião, o pluralismo religioso. Houve uma alteração nesse processo a partir da decisão tomada ano passado pelo Supremo Tribunal Federal, que autorizou a presença do Ensino Religioso confessional nas escolas públicas, este admitido a partir da prerrogativa de direito à liberdade de expressão religiosa do docente e da comunidade escolar como um todo (COSTA; SILVA, 2017).

Contudo, enquanto componente curricular, esta disciplina se propõe a garantir, em seus processos educativos, espaços para discussões que envolvam a formação dos sujeitos, abordando aspectos que favoreçam ao respeito, à diversidade e à alteridade, uma vez que as minorias, ao se politizarem, tornaram-se mais visíveis, buscando o reconhecimento de suas identidades nos campos sociais, culturais e educacionais (LOURO, 2001).
(C) ETD- Educação Temática Digital
Campinas, SP
v.20 n.4
p. $864-886$
out./dez. 2018 
Sendo assim, é objetivo da educação de modo geral, e do Ensino Religioso em particular, identificar e estimular conteúdos programáticos que reflitam sobre a vida e suas limitações, haja vista ser função escolar a troca e o diálogo entre diferentes culturas. Entretanto, tais conteúdos programáticos se encontram articulados a um campo mais amplo, o do currículo, que sofre movimentos de disputa, deslocamentos e hibridizações e que por conta disso, não deve ser encarado como algo fechado (SILVA; OLIVEIRA, 2016).

A partir da compreensão de que o currículo escolar é um mecanismo social de cunho ideológico, que define quais culturas devem ter ou não representatividade nos espaços educacionais, foi possível verificar a presença de um discurso majoritário acerca do currículo de Ensino Religioso nas escolas de Recife pesquisadas, discurso este que reverbera ideologicamente a inadequação e a indiferença no trato com as questões de gênero e sexualidade. Sua predominância redunda, nas salas de aula, em práticas estigmatizadoras, tornando invisível o lugar que mulheres sexualmente marginalizadas, como lésbicas, bissexuais e transexuais ocupam nos conteúdos trabalhados nessa disciplina (OLIVEIRA, 2015, 2016).

Os dados coletados na presente pesquisa apontam assim, para a necessidade de reflexões, por parte de todos que compõem o espaço e a comunidade escolar, sobre a presença do Ensino Religioso nas escolas públicas. Neste caso, faz-se necessário examinar o trabalho que vem sendo feito em torno de problemáticas inerentes à atual sociedade tais como diversidade sexual e religiosa e identidade de gênero e orientação sexual, pois ideologias como a que identificamos entre os entrevistados, reforçam preocupações acerca da não consolidação de uma agenda de trabalho com os temas transversais gênero e sexualidade na esfera educacional.

É fato que "... à escola tem sido atribuída a responsabilidade de preencher algumas lacunas, cabendo aos professores das diversas áreas do conhecimento a tarefa de orientação quanto à sexualidade, numa perspectiva transdisciplinar" (LIRA e JOFILI, 2010, p. 24), porém, nem sempre os professores apresentam condições de exercer esse papel, sentindo-se inseguros e, justamente por isso, uma forte ideologia presente nas falas dos abordados, a da legalidade, era acionada para considerar aspectos relativos aos processos pedagógicos do ER.

Diante disso, o discurso de cunho biológico ganha cada vez mais espaço, reforçando ideologias essencialistas nas falas dos professores posto que, estes concebem a sexualidade, restringindo-a apenas a informações físico-anatômicas, devendo por isso, os temas transversais aqui sublinhados, ficar a cargo apenas das ciências da natureza como a Biologia, ou da saúde, como a Educação Física. Essa ideologia essencialista não compreende, todavia, que é no espaço das várias disciplinas, entre outras, a de Ensino Religioso, que a educação

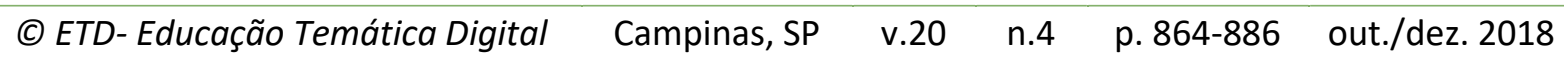


sexual deve ser contemplada e problematizada em sua complexa constituição social e cultural (SILVA; OLIVEIRA, 2016).

Desse modo, os discursos ao redor do Ensino Religioso suscitam a necessidade de questionamentos quanto ao processo de formação oferecido pela escola aos indivíduos, visto que no próprio currículo deste, questões fundamentais como diversidade sexual e de gênero apresentam-se como seus principais desafios; porém, embora tais temáticas estejam vinculadas ao próprio exercício da cidadania, uma vez que perpassam pela discussão do respeito por si e pelo outro, ainda não possuem o espaço e a atenção devida na disciplina em tela, evidenciando equívocos, como o referente à indiferença às temáticas sobre gênero e sexualidade. Tal postura pode comprometer conquistas democráticas no campo da diversidade de gênero e sexual (OLIVEIRA, 2014, 2015, 2016).

Ainda sobre isso, faz-se importante colocar que no debate sobre a presença de uma disciplina que aborda as religiões nas escolas públicas e que envolve a questão da laicização, cometemos comumente um equívoco, este é o de acharmos que o termo laicização se opõe ao termo religião e este não é o caso, tendo em vista que tal conceito (o de laicização), elaborado entre os séculos XVIII e XIX, teve como um de seus fins, ante a conjuntura de construção dos Estados Modernos, contrapor-se à presença das religiões na vida pública, mas não na esfera privada.

No Brasil, a propalada laicização nos espaços públicos, em sua realização, não se deu, à medida que a presença das religiões cristãs, sobretudo a católica, sempre foi grande, e nas escolas públicas isso não foi diferente. Neste caso, as idas e vindas na relação entre Estado e religião sempre tiveram como lugar de negociação a área da educação por meio da disciplina de Ensino Religioso e essa relação emblemática, durante longos anos e através das diversas constituições, favoreceu a uma religião, no caso a Católica (GIUMBELLI, 2008).

Assim, por época de elaboração da vigente LDB (BRASIL, 1996), reflexos das lutas travadas entre laicos e defensores do Ensino Religioso, lutas estas estabelecidas na área da educação desde os anos trinta do século passado entre de um lado, os escolanovistas, favoráveis a uma educação pública, gratuita e contrários à presença religiosa nas escolas públicas, e do outro, setores religiosos, sobretudo católicos, ocorreram, e elas tiveram e ainda têm que negociar hoje, especialmente depois da valorização e exigência do trato com a temática da diversidade nos currículos das várias disciplinas escolares (PENTEADO, 2015).

Sobre esse debate, isto é, da presença de uma disciplina que aborda religiões no espaço público, expomos algumas reflexões: a primeira, ter uma religião implica em se apoiar em valores, e nós ao adentrarmos em qualquer espaço, seja ele público ou privado, não nos despimos desses valores como tiramos ou trocamos uma roupa. Dessa forma, a presença religiosa encontra-se incrustada na esfera privada e também pública das salas de
(C) ETD-Educação Temática Digital
Campinas, SP
v.20
n.4
p. $864-886$
out./dez. 2018 
aula e teremos em algum momento, gostemos ou não, que problematizarmos dialogarmos/confrontarmo-nos com ela.

Segundo, neste processo de admissão da presença religiosa no espaço público, o Estado, atuando no sentido de garantir a pluralização cultural e a democracia, deve para isso, abrir mão de neste espaço, o público, incluindo aí as escolas e as salas de aula, de defender ou privilegiar, seja diretamente ou sutilmente, qualquer religião, evitando recair no tão criticado proselitismo cristão que marcou a história do Brasil.

Para isso, entre outros, um cuidado faz-se fundamental, este é o de como lidar com a diversidade religiosa nas escolas, especialmente as públicas? Neste caso, o problema reside em querer tratar uma ou algumas religiões como "verdades", consequentemente outras como mentiras, e não como fenômenos culturais e sociais, portanto, como criações humanas. Diante disso, a abordagem, devendo se concentrar sobre as cosmologias e/ou cosmovisões das diversas religiões, não importando se minoritárias ou não, deve assumir uma preocupação com o investimento na compreensão das religiões como instituições/construções antropológicas e históricas (OLIVEIRA, 2015, 2016).

Com isso evita-se cair na armadilha das "verdades religiosas", oriunda de perspectivas teológicas e transcendentais, e se entra no debate de posição imanente, em torno de abordagens e reflexões de valores culturais e sociais advindos das pertenças religiosas, abrindo espaço assim para a presença de diferentes visões, inclusive as não religiosas, as atéias, as agnósticas e as dos sem religião, por exemplo. Dessa forma, o trato com o gênero e a sexualidade pode vir a se apresentar de modo mais palatável para gestores e docentes de Ensino Religioso, à medida que essas temáticas passam a ser percebidas politicamente como eixos de reflexão sociocultural, sendo importantes para o entendimento acerca de lugares que instituições e cosmovisões religiosas estabeleceram/estabelecem para mulheres sexualmente estigmatizadas como as lésbicas, as bissexuais e as transexuais.

\section{REFERÊNCIAS}

AQUINO, Camila; MARTELLI, Andrea Cristina. Escola e educação sexual: uma relação necessária. SEMINÁRIO DE PESQUISA EM EDUCAÇÃO DA REGIÃO SUL. 2012, Porto Alegre.

Anais eletrônicos do IX ANPED Sul. Porto Alegre: UFRGS. Disponível em: http://www.ucs.br/etc/conferencias/index.php/anpedsul/9anpedsul/paper/viewFile/1105/ 800 Acesso em: 02 de dez. 2015.

BRASIL. Constituição da República Federativa do Brasil: texto constitucional promulgado em 05 de outubro de 1988. Brasília, DF: Senado Federal, Coordenação de Edições Técnicas, 2016.

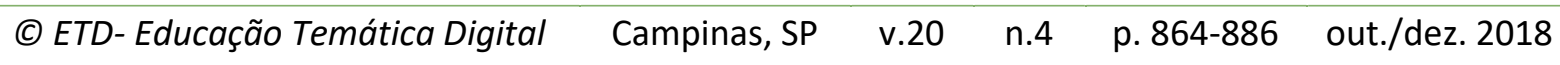


BRASIL. Lei de diretrizes e bases da educação no 9394/96. Brasília, DF: Presidência da República, 1996.

BRASIL. Lei Maria da Penha no 11.340. Brasília, DF: Presidência da República, 2006.

BHABHA, Homi K. O local da cultura. Belo Horizonte: UFMG, 2005.

BUTLER, Judith. Problemas de gênero: feminismo e subversão da identidade. Rio de Janeiro: Civilização Brasileira, 2003.

BUTLER, Judith. Cuerpos que importan: sobre los límites materiales y discursivos del "sexo". Buenos Aires, Barcelona, México: Paidós, 2008.

COSTA, lasmin; SILVA, Bartolomeu. Ensino religioso confessional é aprovado pelo STF. Disponível em: https://noticias.cancaonova.com/brasil/supremo-autoriza-ensino-religiosoconfessional-nas-escolas-publicas-2/. Acesso em: 30 de set. 2017.

FACCHINI, Regina. Sopa de letrinhas? Movimento homossexual e produção de identidades coletivas nos anos 90. Rio de Janeiro: Garamond, 2005.

FOUCAULT, Michel. História da sexualidade I: a vontade de saber. São Paulo: Edições Graal, 2007.

GIUMBELLI, Emerson. A presença do religioso no espaço público: modalidades no Brasil. Religião \& Sociedade, v.28, n.2, p. 80-101, Rio de Janeiro, Instituto de Estudos Religiosos (ISER), 2008.

HARAWAY, Donna. Manifesto ciborgue: ciência, tecnologia e feminismo-socialista no final do século XX. In: SILVA, Tomaz Tadeu da. (Org.). Antropologia do ciborgue: as vertigens do pós-humano. Belo Horizonte: Autêntica, 2009.

LIRA, Andréia; JOFILI, Zélia. O tema transversal Orientação Sexual nos PCN e a atitude dos professores: convergentes ou divergentes? REMPEC - Ensino, Saúde e Ambiente, v.3, n.1, p. 22-41, abr./2010.

LOPES, Alice Casimiro; MACEDO, Elizabeth. Teorias de currículo. São Paulo: Cortez, 2011.

LOURO, Guacira L. Teoria Queer: uma política pós-identitária para a educação. Estudos Feministas, v. 9, n. 2, p. 541-553, 2001.

MIRANDA, Marcelo Henrique G. de. Condensação de sentidos e paródia: categorização social sobre sexo, gênero e sexualidade. 2013. 216 f. Tese (Doutorado em Sociologia) Universidade Federal de Pernambuco, Recife, 2013.

MISKOLCI, Richard. Teoria Queer: um aprendizado pelas diferenças. Belo Horizonte: Autêntica, 2012.

OLIVEIRA, Aurenéa Maria de; SILVA, Drance Elias da. Alteridade X intolerância: diretrizes curriculares que podem embasar, mais democrática e pluralmente o Ensino Religioso.

Revista Teias, v. 13, n. 27, p. 139-160, jan./abr. de 2012.

OLIVEIRA, Aurenéa, Maria de; MIRANDA, Marcelo, Henrique G. de. A visibilidade de corpos gendrados: interfaces com o campo político e educacional. In: VII SEMINÁRIO

(C) ETD-Educação Temática Digital Campinas, SP $\quad$ v.20 $\quad$ n.4 $\quad$ p.864-886 out./dez. 2018 
INTERNACIONAL REDES, 2013, Rio de Janeiro. Anais - As redes educativas e as tecnologias: transformações e subversões na atualidade. Rio de Janeiro: UERJ, 2013, p. 1-15.

OLIVEIRA, Aurenéa Maria de. Tolerância, intolerância e diferenças: como o currículo da disciplina de Ensino Religioso lida com questões que envolvem pluralidade religiosa e sexualidade nas escolas estaduais e municipais de Recife. Projeto de pesquisa aprovado pela CHAMADA UNIVERSAL - MCTI/CNPq N $\cong 14 / 2013$.

OLIVEIRA, Aurenéa Maria de. Pluralismo e alteridade: o lugar que os segmentos LGBTTTI ocupam no currículo da disciplina de Ensino Religioso nas escolas estaduais e municipais de Recife (PE). Revista Pistis \& Práxis, v .6, n .2 , p. 611-625, 2014.

OLIVEIRA, Aurenéa Maria de. Relações de gênero e orientação sexual no currículo da disciplina de Ensino Religioso em escolas estaduais e municipais de Recife. Horizonte:

Revista de Estudos de Teologia e Ciências da Religião (Online), v.13, n. 39, p.1510-1533, 2015.

OLIVEIRA, Aurenéa Maria de. Diferença sexual e religiosa no currículo de Ensino Religioso em escolas de Recife. Revista Eletrônica de Educação (São Carlos), v.10, n. 1, p.128-142, 2016.

ORLANDI, Eni Pulcinelli. Terra à vista, discurso do confronto: velho e novo mundo. São Paulo: Cortez, 1990.

ORLANDI, Eni Pulcinelli. Análise de discurso: princípios e procedimentos. Campinas, SP: Pontes, 1999.

PÊCHEUX, Michel. Semântica e discurso: uma crítica à afirmação do óbvio. Campinas, SP: Unicamp, 1988.

PÊCHEUX, Michel. Discurso: estrutura ou acontecimento. Campinas, SP: Pontes, 1997.

PENTEADO, Luiz Gonzaga Moura. Entre dizeres, saberes e fazeres: os espaços vivenciados pelo Ensino Religioso no currículo da escola pública em Recife no período de 1996 à 2014. 2015. 141 f. Dissertação (Mestrado em Educação) - Universidade Federal de Pernambuco, Recife, 2015.

PRECIADO, Beatriz. Manifiesto contra-sexual: prácticas subversivas de identidad sexual. Madrid: Opera Prima, 2002.

PRECIADO, Beatriz. Multitudes Queer: notas para uma política de los “anormales". Revista Multitudes, n. 12, París, 2003.

PRECIADO, Beatriz. Terror anal: apuntes sobre los anormales días de la revolución sexual. HOCQUENGHEM, Guy. El deseo homosexual. Espanha: Melusina, 2009.

SILVA, Maria Amanda Micaely P. da; OLIVEIRA, Aurenéa Maria de. Relações de gênero e diversidade sexual: qual o lugar que mulheres sexualmente marginalizadas ocupam no currículo da disciplina de Ensino Religioso em escolas estaduais e municipais de Recife.

Relatório final PIBIC/UFPE/CNPq. Recife, ago./2015 a jul./2016.

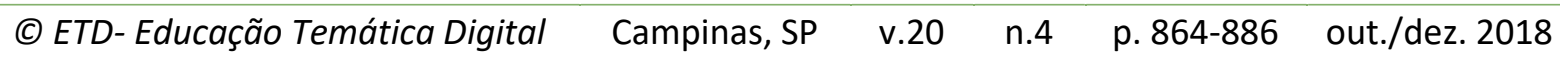


WEEKS, Jeffrey. O corpo e a sexualidade. Louro, Guacira L. (Org.). O corpo educado: pedagogias da sexualidade. Belo Horizonte: Autêntica, 2000.

\section{Agradecimentos}

Agradecemos à UFPE/CNPq pelo apoio e bolsa de iniciação científica concedida (2015-2016). Igualmente agradecemos ao CNPq pela aprovação de projeto de pesquisa no edital universal, chamada $\mathrm{MCTI} / \mathrm{CNPq} \mathrm{N} \cong 14 / 2013$. Sem os recursos advindos, este artigo e pesquisa teriam muita dificuldade de realização.

* Revisão gramatical do texto sob a responsabilidade dos autores 